Mote: «Se a mulher se revolta contra o homem, nada fica intacto»

\title{
Pussy Riot, Femen e as Três Marias: Feminismos zangados e o corpo das mulheres em luta
}

\author{
Ana Margarida Dias Martins \\ Universidade de Exeter
}

Quando o burguês se revolta contra o rei, ou quando o colono se revolta contra o império, é apenas um chefe ou um governo que eles atacam, tudo o resto fica intacto, os seus negócios, as suas propriedades, as suas famílias, os seus lugares entre amigos e conhecidos, os seus prazeres. Se a mulher se revolta contra o homem nada fica intacto; para a mulher, $o$ chefe, a política, o negócio, a propriedade, o lugar, o prazer (bem viciado), só existem através do homem.

"Extractos do diário de D. Maria Ana, descendente directa de D. Mariana sobrinha de D. Mariana Alcoforado, e nascida por volta de 1800 ", Novas cartas Portuguesas 
A carta de onde este mote foi retirado versa sobre o potencial da revolta e do protesto enunciado no feminino. De acordo com os extractos retirados do seu diário, D. Maria Ana, descendente directa de D. Mariana sobrinha de D. Mariana Alcoforado, não consegue encontrar esperança no andar dos anos: "Entre Mariana sobrinha e eu, vieram quatro gerações decorativas, absorventes, que cultivaram as delícias da paixão e as cartas de estilo amoroso" (Barreno/Horta/Costa 2010: 141). Contrariamente às que a precederam, Maria Ana não é mãe, nem é esposa. Tudo o que faz é escrever, antagonica e ferozmente, mas ninguém entende a sua escrita como saber. E como não há igualdade na relação homem-mulher, também não há repouso para a guerreira. Desta forma, conclui, "fica sem sentido a vida de mulheres como eu" (idem: 143). A única coisa a fazer é viver uma vida de recusa, sozinha, uma vida a dizer "não." Esta minha intervenção salta no escuro desse "não," que é antagónico, mas também desiludido. “Fará sentido vida que é só recusa?”, pergunta-nos ela (ibidem). 0 problema desta Maria Ana é, portanto, actualíssimo. Como recusar, para quê protestar, como revolucionar?

Em Junho de 2012, assisti ao nascimento, através da Internet e das redes sociais, do movimento "Que se Lixe a Troika! Queremos as nossas vidas!", responsável pela organização de manifestações como, por exemplo, a de 15 de Setembro de 2012, que levou um milhão de pessoas à rua em várias cidades portuguesas num protesto nacional contra as medidas de austeridade impostas pelo governo. Ainda assim, como nota uma reportagem no jornal Público, “eram muitos os que, fora do protesto (de Outubro 2013), o via simplesmente passar: Manifestar-me para quê? 0 que é que muda?" (Camarão et al. 2013).

Numa época de grandes actos de mobilização colectiva em que protestar e aparecer se tornou um direito que parece não levar a lado nenhum, a voz da nossa Maria Ana ganha actualidade, e acompanha os passos solitários de quem vê o protesto passar e pensa, "Para quê protestar? Como revolucionar?"

É fundamental notar que Maria Ana admite estar só - “Onde estão os meus companheiros de luta?" - e é exactamente essa solidão que coloca em causa o poder do seu protesto. Ser corpo feminino em luta, na rua contra políticas, ou em casa contra o marido, depende da presença de outros corpos em luta. Agir politicamente equivale a agir em grupo, 
e depende do nosso aparecimento perante outros corpos. No seu recente trabalho sobre política da rua, intitulado, "Bodies in Alliance and the Politics of the Street" (2011), Judith Butler avança a hipótese: se queremos entender o poder e o efeito dos protestos públicos, temos que nos consciencializar de que toda e qualquer acção tem uma dimensão corporal, e que, por isso, toda e qualquer acção depende daquilo que o corpo pode fazer, especialmente em grupo.

Se uma Maria Ana, sozinha e em casa, pouco pode mudar, o que podem várias Marias Anas na rua e em grupo? Imaginemos então, irmãs minhas, dois grupos de Marias Anas. Enquanto uma sobe a um telhado de balaclava na cabeça, logo a outra desce as escadas a correr e aparece, de repente, de peito ao léu, em frente ao Putin.

Enceno nesta intervenção o registo de Novas Cartas Portuguesas e exprimo uma equivalência estratégica entre as autoras portuguesas e estes dois colectivos femininos Pussy Riot e Femen - não para homogenizar as lutas e aplicar uma etiqueta feminista a todas, mas para chamar a atenção para a semelhança entre estes três colectivos no que diz respeito à forma como foram e são despoliticizados, devido a uma visibilidade excessiva do corpo feminino na praça pública, em tempos e modos diferentes, é claro.

0 modelo (estereotipado) de um feminismo zangado, cheio de raiva, significa, hoje, substancialmente, estas duas coisas: resistir de balaclava à la Pussy Riot ou mostrar os seios na rua, estilo Femen. Como pensar as possibilidades abertas por estes dois tipos de protesto que dependem do corpo feminino em luta e em grupo, na rua? De que forma é que este protestar em grupo contribui para reformular a ideia de irmandade no século XXI?

As Pussy Riot e as Femen distanciam-se entre si pela forma como as suas activistas lidam com a individualidade física feminina: se o feminismo radical das Pussy Riot depende das máscaras que conferem anonimato às suas manifestantes, o "sextremism" das Femen transforma o corpo nu num instrumento de luta e confronto agressivo, mas não violento. 0 primeiro grupo defende o anonimato como forma de luta. 0 segundo grupo, em contraste, explora a individualidade das suas militantes, defendendo que a imagem corporal tem o poder de atacar directamente a construção da mulher enquanto objecto sexual na esfera privada. Na realidade, as Pussy Riot e as Femen só aparentemente se distanciam, na medida 
em que os seus protestos revelam os dois lados da mesma moeda: vestidas ou nuas, escondidas ou aparecidas, as mulheres são corpo. Como pensar então esse corpo feminino aparecido na rua, em protesto nu ou vestido? Nesta minha breve reflexão sobre as possibilidades abertas pelo corpo feminino em luta na rua, parto da hipótese de que temos que repensar a forma como enfrentamos a visibilidade do corpo feminino, para podermos chegar ao "espaço da aparição" de que nos fala Butler, a partir de Hannah Arendt. Para Arendt, diz-nos Butler, o espaço da aparição é "the space where I appear to others as others appear to me" (Butler 2011). Mas Butler vai mais longe, argumentando que a acção de aparecer é criada e permitida pelo próprio espaço, e que também o espaço se modifica por causa dessa aparição do corpo: "action is always supported, and (...) it is invariably bodily, even in its virtual forms" (...). The material supports for action are not only part of the action, but they are also what is being fought about" (Butler 2011). Por outras palavras, o espaço da aparição (que é também o espaço da mudança e da revolução) depende de uma simultaneidade: a simultaneidade do espaço a agir sobre os corpos e dos corpos a agirem sobre o espaço.

Para melhor pensarmos a ocorrência desta simultaneidade - e assim descortinarmos um pouco do valor do protesto público em grupo e entre mulheres - irei concentrar-me na forma como as manifestações das Femen e Pussy Riot reformulam, e são reformuladas, pelo espaço onde a sua aparição pública acontece.

Pussy Riot é um colectivo feminista russo sediado em Moscovo e criado em Agosto de 2011. O colectivo é composto por um pequeno grupo de mulheres entre os 20 e os 33 anos que organiza "guerrilla gigs" não autorizados, estilo "flashmob" em locais públicos. Estas manifestações artísticas são gravadas, editadas e transformadas em videos musicais, e colocadas na Internet. As letras das suas cancões abordam temas como o feminismo, os direitos LGBT, e em especial o estado patriarcal promovido pela política de Vladmir Putin, bem como as suas relações com os líderes da Igreja russa ortodoxa. Durante estes mini-concertos, organizados em locais inusitados e sem aviso prévio, estilo "flash mob," as Pussy Riot endossam vestidos e collants de cores fortes e balaclavas coloridas: gorros justos que 
cobrem a cabeça até ao pescoço ou até aos ombros, com abertura para os olhos, nariz e boca.

Numa intervenção acerca do colectivo russo, Slavoj Žižek explica a razão pela qual as Pussy Riot envergam balaclavas: "they are artists who embody an Idea. This is why they wear balaclavas: masks of deindividualization, of liberating anonymity. The message of their balaclavas is that it doesn't matter which of them are arrested - they're not individuals, they're an Idea!" (Žižek 2012).

Žižek tem razão, mas há um problema com discursos que explicam as Pussy Riot começando com aquele que serve para esconder o corpo. 0 problema destes discursos é que eles acabam por dar mais importância à forma como o espaço público age sobre os corpos das Pussy Riot (esconder a cara é mais uma reação do que uma acção), em vez de pensar a simultaneidade de acções em jogo nos seus protestos. A palavra "balaclava" surge no final do século XIX, para nomear os gorros utilizados pelos soldados na Guerra da Crimeia (1854). (Os gorros ganham o nome do Porto de Balaclava na Crimeia). Com a balaclava, portanto, as Pussy Riot defendem-se, são desleais para com um código regulatório de representação do corpo feminino na esfera pública: "We cover our heads because we oppose the very idea of using female faces as a trademark for promoting any sort of goods or services" (De Bode 2014). De facto, usar balaclava, cobrir o corpo, assinala a forma como o espaço público age sobre as mulheres. Mas a balaclava diz-nos pouco sobre a forma como as Pussy Riot tentam agir sobre o espaço público.

Neste contexto, poucos notam que, em vez da cara, elas dão a voz. Como explica Nadezhda Tolokonnikova: "We didn't know how to play, like so many people, but we wanted to get our message across as loudly as possible so everybody could hear us" (Tolokonnikova, cit. in Butler 2011). O ênfase na voz, no prazer de se fazerem ouvir, e não ver, transfere a percepção de individualidade e personalidade da superfície corporal para um lugar dentro do corpo que fabrica o som. Como nos lembra Adriana Cavarero no seu livro, For More than One Voice, voz também é corpo: "feminised from the start, the vocal aspect of speech and, furthermore, of song appear together as antagonistic elements in a rational, masculine sphere that centres itself, instead, on the semantic. To put it 
formulaically: woman sings, man thinks" (Cavarero 2005: 6). Apesar de a voz das Pussy Riot vir de um espaço que parece estar fora da esfera pública e masculina, é politicamente necessário ouvir essa voz, para vermos até que ponto ela consegue agir sobre, e romper com uma visão logocêntrica do mundo.

Portanto, a vontade de falar sobre a balaclava, e de conhecer a cara por detrás da balaclava desvocaliza as Pussy Riot, pois dá prioridade ao visual, por oposição ao auditivo. É talvez por esta razão que, assim que Nadya e Masha foram obrigadas a despir a balaclava e a mostrar a sua individualidade, durante o pocesso judicial aberto no seguimento da sua actuação na catedral de Moscovo, estas deixaram de ser reconhecidas como elementos das Pussy Riot pelo colectivo. De repente, todos se concentraram no que a balaclava escondia, em vez de ouvirem as diversas vozes "desencorporadas" que continuam a escapar do buraco da boca da balaclava. Proponho, então, que a Ideia por detrás da balaclava não é só a do anonimato libertador, como escreve Žižek, mas também a do logocentrismo surdo, que não quer ouvir a voz das mulheres, em toda a sua particularidade e capacidade vocal de relação. Esta incapacidade de ouvir é perniciosa, pois ignora um dos aspectos mais importantes que ligam as Pussy Riot a quem as vê protestar. Como sugere Cavarero: "even those that value 'dialogue' and 'communication' remain imprisoned in a linguistic register that ignores the relationality already put in action by the communication of voices" (Cavarero 2005: 16). 0 poder performativo da voz múltipla das Pussy Riot, a gritar canções punk nos telhados das casas e na catedral, é o que lhes permite agir sobre esse espaço, reconfigurando consideravelmente o que significa abrir a boca em público.

Como já foi referido, as Pussy Riot aproximam-se bastante do grupo Femen na medida em que ambos os grupos trazem o corpo feminino para a esfera pública. Se o modelo Pussy Riot o mostra escondendo-o, o modelo Femen esconde-o mostrando-o. Nos dois casos, a aparição do corpo feminino no espaço público demonstra que a divisão entre as esferas pública e privada é uma ficção que legitima o poder. As Femen são um grupo de protesto criado na Ucrânia em 2008. 0 grupo defende um novo tipo de activismo feminino que denominam por "sextremism," um activismo agressivo e provocador mas não violento. Nas suas aparições em público, as Femen transformam o seu corpo, nu da cintura para cima 
(e às vezes da cintura para baixo, num instrumento activo de confronto das instituições patriarcais, tais como a Igreja, a indústria sexual e as ditaduras.

A negociação do espaço público coordenado pelo gupo Femen também envolve uma modificação da paisagem auditiva. Contrariamente às Pussy Riot, as manifestantes não cantam, mas repetem slogans aos gritos, de braços no ar e aos saltos, ou então de braço dado, irritando a paz pública e a paciência das autoridades. Gritar na rua, em público e sem roupas, é uma forma muito eficaz de incitar a acção policial. As manifestantes não querem que a polícia as deixe em paz. Elas incitam-nos a que as agarrem. Isto porque o contacto físico entre elas e eles é uma parte fundamental do protesto, embora esta seja, uma vez mais, uma questão que raramente é discutida como parte do protesto. Não é o toque que é enfatizado pelos meios de comunicação social, mas sim o olhar masculino sobre o corpo. De facto, a polícia é obrigada a tocar o corpo das manifestantes. Mas como é que se toca o corpo nú e pintado de uma mulher, que muitos descreveriam como atraente, no meio da rua, entre o flash dos fotógrafos e os telemóveis iluminados dos transeuntes? Onde colocar a mão? Como evitar o apalpão acidental, o olhar menos dignificador? Incitar ao toque é, neste caso, uma acção política, pois contribui para uma transformação da forma como se olha e se toca o corpo feminino subitamente reposicionado na esfera pública, precário mas insistente, nú mas insolente, multiplicado em imagem e discurso, e efectivamente transformando a imagem e o discurso patriarcal na medida em que expõe a dependência entre corpos: entre os corpos que se manifestam, e entre os corpos que se manifestam e os que observam e patrulham a manifestação. Cria-se uma dependência, e é essa dependência que produz uma janela de transformação (do) real.

Esse confronto é essencial. É precisamente no momento em que os corpos das manifestantes são tocados pelas forças da autoridade que o protesto surge de facto, e se materializa perante os nossos olhos. 0 que vemos nesse momento do toque é o espaço público a agir sobre os corpos nus das mulheres, ao mesmo tempo que elas agem sobre o espaço público. 0 corpo policial masculino é obrigado a redescobrir-se neste toque que evita as partes íntimas femininas e se sente incomodado com a pele quente e pintada das manifestantes perante as câmaras. É através do toque do corpo feminino no espaço público 
que os polícias se transformam numa parte essencial do protesto, pois ao tentarem negociar formas mais neutras de contacto físico, surgem eles próprios enquanto corpos sexuados, e não legitimizados - vulneráveis de certo modo. Com esse toque, portanto, nada, ou muito pouco, fica intacto, como deseja e escreve a nossa Maria Ana de 1800, em Novas Cartas Portuguesas, no mote que me coube.

\section{Nota}

${ }^{1}$ Intervenção de Judith Butler na Aula Magna em Veneza (Butler 2011). 


\section{Bibliografia}

Arendt, Hannah (1958), The Human Condition, Chicago, The University of Chicago Press.

Barreno, Maria Isabel Maria Teresa Horta/Maria Velho da Costa (2010), Novas Cartas Portuguesas, Edição anotada, Org. Ana Luísa Amaral, Lisboa, Dom Quixote.

Butler, Judith (2011), "Bodies in Alliance and the Politics of the Street," Aula Magna, Veneza, 7 setembro, <www.eipcp.net/transversal/1011/butler/en> [Acedido a 16 de maio 2016].

Camarão, Teresa, et al. (2013), "Milhares de pessoas marcham contra a troika,” Público, 26 de outubro, <www.publico.pt/sociedade/noticia/centenas-de-pessoas-marcham-contra-atroika-1610422\#/0> [Acedido a 16 de maio 2016].

Cavarero, Adriana (2005), For More than One Voice: Towards a Philosophy of Vocal Expression, Stanford, Stanford University Press.

De Bode, Lisa (2014), “Pussy Riot members announce split with freed duo," Aljazeera America, 6 de fevereiro, <http://america.aljazeera.com/articles/2014/2/6/pussy-riotmembersannouncesplit.html> [Acedido a 23 dezembro 2016].

Guaraldo, Olivia (2012), "Thinkers that Matter: On the Thought of Judith Butler and Adriana Cavarero", AG About Gender: International Journal of Gender Studies, vol. 1, no. 1, 92-117.

Žižek, Slavoj (2012), “The True Blasphemy: Slavoj Žižek on Pussy Riot”, 7 de agosto, <http://chtodelat.wordpress.com/2012/08/07/the-true-blasphemy-slavoj-zizek-onpussy-riot/> [Acedido a 16 maio 2016]. 
Ana Margarida Dias Martins é professora associada de Estudos Portugueses na Universidade de Exeter. Doutorou-se em Literaturas de Expressão Portuguesa pela Universidade de Manchester e lecionou nas universidades de Cambridge e King's College London. É autora de várias publicações nas áreas dos Estudos de Mulheres, Pós-coloniais e Feministas. Publicou a monografia Magic Stones and Flying Snakes: Gender and the Postcolonial Exotic in the Work of Paulina Chiziane and Lídia Jorge (Peter Lang, 2012) e coeditou The Luso-Tropical Tempest: Postcolonial Debates in Portuguese (Bristol University Press, 2012). É ainda co-autora de Authentic Recipes from Around the World (Ceredigion, 2015). 